\title{
Desempenho de sistema de tratamento de lixiviado de aterro sanitário com recirculação do efluente
}

\section{Performance of a sanitary landfill leachate treatment system with effluent recirculation}

\author{
Cláudia Lavina Martins \\ Engenheira Sanitarista e Ambiental pela Universidade Federal de Santa Catarina (UFSC). Mestre e Doutoranda em Engenharia Ambiental pela UFSC \\ Armando Borges de Castilhos Júnior \\ Professor Associado I do Departamento de Engenharia Sanitária e Ambiental da UFSC. Pesquisador nível 2 do Conselho Nacional de Desenvolvimento \\ Científico e Tecnológico (CNPq)
}

Rejane Helena Ribeiro da Costa

Professora Titular do Departamento de Engenharia Sanitária e Ambiental da UFSC. Pesquisadora nível 1B do CNPq

\begin{abstract}
Resumo
O objetivo deste estudo foi avaliar o desempenho de um sistema de tratamento de lixiviado de aterro sanitário, em escala piloto, formado por três lagoas em série (L1, L2 e L3) seguidas por um filtro de pedras (FP). Foram estudadas três condições operacionais, verificando-se o efeito da recirculação do efluente da L3 para a L1: 0, 50 e 100\% da vazão. O sistema absorveu bem as flutuações de cargas, apresentando remoções superiores a $80 \%$ para DBO ${ }_{F}, 70 \%$ para DQO e 98\% para nitrogênio amoniacal. Na lagoa L2 houve nitrificação parcial, com acúmulo de nitritos. Ocorreu presença marcante do gênero Chlamydomonas nas lagoas L2 e L3 fotossintéticas. Observou-se diminuição da toxicidade do lixiviado, com reduções superiores a 95\% na saída do sistema. A melhor eficiência de remoção para as três condições operacionais estudadas foi obtida com 100\% de recirculação.
\end{abstract}

Palavras-chave: lixiviado de aterro sanitário; lagoas de estabilização; recirculação; remoção de amônia; detoxificação.

\section{Abstract}

The objective of this study was to evaluate the performance of a landfill leachate treatment system, at pilot scale, formed by three in series ponds ( $\mathrm{L} 1$, $\mathrm{L} 2$, and L3) followed by a rock filter. Three operational conditions were studied, assessing the effluent recirculation effect from L3 to L1: 0,50 and 100\% of the flow rate. The system assimilated well the load fluctuations, showing removal efficiencies over $80 \%$ for $\mathrm{BOD}_{\mathrm{F}}, 70 \%$ for $\mathrm{COD}_{\mathrm{T}}$ and $98 \%$ for ammonia. In the $\mathrm{L} 2 \mathrm{pond}$ there was partial nitrification with nitrite accumulation. It was observed an outstanding presence of the Chlamydomonas gender in photosynthetic ponds L2 and L3. A reduction of the toxicity from the landfill leachate was observed, with reduction of over $95 \%$ in the system output. The better removal efficiency for the three studied operational conditions was obtained for $100 \%$ of recirculation.

Keywords: sanitary landfill leachate; stabilization ponds; recirculation; ammonium removal; detoxification.

\section{Introdução}

O risco de contaminação das águas superficiais e subterrâneas pelos lixiviados é considerado um dos impactos mais significantes da deposição de resíduos em aterros (KJELDSEN; CHRISTOPHERSEN, 2001). Em geral, os lixiviados são caracterizados por apresentarem concentrações elevadas de compostos orgânicos, amônia e sais inorgânicos, incluindo, em alguns casos, metais pesados (GANIGUÉ et al., 2007). Ao mesmo tempo, sua composição depende de fatores complexos, incluindo propriedades do solo, condições climáticas, composição das células de aterramento, idade e operação do aterro (SILVA; DEZOTTI; SANT'ANNA, 2004).

Para remoção dos poluentes contidos nos lixiviados, são utilizados tratamentos físico-químicos e biológicos (WISZNIOWSKI et al., 2006; ALTINBAS, 2009). Porém, muitas vezes, nem o tratamento biológico nem o físico-químico, separadamente, alcançam elevada eficiência, em razão de dois fatores principais: (1) presença significante de moléculas orgânicas de elevado peso molecular; e (2) efeitos 
inibidores de compostos orgânicos, sais inorgânicos e metais para os micro-organismos responsáveis pelo tratamento (GOTVAJN; TIŠLER; ZAGORC-KONČAN, 2009). Para Hossaka et al. (2009), a remoção de amônia é um dos principais aspectos que deve ser considerado no tratamento dos lixiviados, devido aos seus efeitos tóxicos para o meio ambiente, além de atender aos padrões de emissão impostos pelos órgãos ambientais. Testes de toxicidade usando vários organismos teste (Vibrio fisheri, Daphnia similes, Artemia salina, Brachydanio rerio etc.) confirmaram o perigo potencial dos lixiviados (SISINNO et al., 2000; RENOU et al., 2008) e a necessidade de tratamento destes, de forma a colocá-los dentro dos padrões exigidos para lançamento nos corpos receptores.

As lagoas de estabilização são largamente aplicadas no Brasil para o tratamento dos lixiviados de aterros sanitários, principalmente devido às condições climáticas favoráveis e disponibilidade de área territorial. Vários fatores contribuem para tornar o tratamento em lagoas uma opção interessante para esse tipo de efluente, tais como: apresentam baixo custo de implantação e manutenção; podem operar em condições de flutuações das cargas aplicadas; conseguem remover compostos orgânicos, nitrogênio, fósforo e micro-organismos patogênicos (FRASCARI et al., 2004). Utiliza-se com grande frequência sistemas de lagoas em série (anaeróbias, facultativas, maturação), onde ocorre a remoção da matéria orgânica e inorgânica dos lixiviados, pela ação conjugada das bactérias e do fitoplâncton. Estudos realizados relatam, no entanto, as dificuldades que os sistemas de lagoas apresentam na remoção dos compostos refratários, causadores de elevada demanda química de oxigênio (DQO), e na remoção de amônia, apresentando geralmente concentrações finais efluentes superiores àquelas exigidas pelos órgãos ambientais (CASTILHOS JR. et al., 2009).

Dentro desse contexto, o objetivo geral deste trabalho foi avaliar o efeito da recirculação do efluente sobre o desempenho de sistema de tratamento de lixiviado de aterro sanitário, visando à melhora na remoção de DQO e amônia; dessa forma, pode contribuir para o avanço do conhecimento sobre o funcionamento de sistemas de lagoas tratando lixiviado de aterro sanitário, para futuros projetos nessa área.

\section{Material e métodos}

O lixiviado bruto utilizado nesta pesquisa era proveniente do Aterro Sanitário de Tijuquinhas, em Biguaçú, Santa Catarina, latitude $27^{\circ} 21^{\prime} 4717^{\prime \prime} S$ e longitude 48 38'15 52"O, em funcionamento desde 1990. Atualmente, recebe resíduos oriundos de 22 municípios, totalizando uma média de $800 \mathrm{~T} \cdot \mathrm{dia}^{-1}$, podendo chegar a $1.000 \mathrm{~T} \cdot \mathrm{dia}^{-1}$ na época de alta temporada (dezembro a fevereiro). O aterro ocupa uma área aproximada de $624.000 \mathrm{~m}^{2}$, onde são aterrados resíduos sólidos domésticos e hospitalares.

O lixiviado, armazenado em tanque de equalização no aterro sanitário, era encaminhado ao laboratório por transporte em caminhão- tanque, onde era depositado em um tanque de armazenamento de fibra de vidro com capacidade de $5 \mathrm{~m}^{3}$, provido de tampa. Desse tanque, por meio de uma bomba centrífuga (Schneider, BSC-94 - 1/2 $\mathrm{CV}-60 \mathrm{~Hz}$ ), o lixiviado era encaminhado para o tanque de equalização com volume de $1 \mathrm{~m}^{3}$, de onde era bombeado (bomba dosadora Emec - CMSCO 0260PP - 50-60Hz) para o sistema de tratamento, com uma vazão de 200 L.dia ${ }^{-1}$.

O sistema de lagoas de estabilização era constituído por: lagoa anaeróbia (L1), lagoa aerada (L2), lagoa de maturação (L3) e filtro de pedras (FP), em série e em escala piloto (Figura 1). A lagoa L1 possuía formato cilíndrico, enquanto as demais, L2 e L3, tinham formato retangular. Nas entradas e saídas das lagoas L2 e L3 foram instaladas "placas de acrílico" para garantir o direcionamento do lixiviado e evitar curtos-circuitos. O FP possuía enchimento de brita comercial $n^{\circ} 4$ (38-76 mm) e a taxa hidráulica aplicada foi de $0,25 \mathrm{~m}^{3} \cdot \mathrm{m}^{-3} \cdot \mathrm{d}^{-1}$.

Inicialmente, foi estudado o sistema de tratamento com aeração na lagoa L2 - Etapa I. Para isso, foram instalados 2 difusores cerâmicos de ar, que forneciam aeração contínua (24 horas.dia-1 ${ }^{-1}$ à lagoa, alimentados por meio de um compressor de ar com capacidade de aspiração de 77,5 L.min'-1 (Schulz - MSI 2,6ML - $12 \mathrm{CV}-60 \mathrm{~Hz}$ ). Essa etapa teve duração de 11 semanas.

Na sequência dos estudos, o efluente de saída da L3 era recirculado para a L1, por meio de bomba dosadora (Exatta - $1 \mathrm{~A}-50 / 60 \mathrm{H}_{\mathrm{z}}$ ). Foram estudadas duas condições operacionais de recirculação: Etapa II - 50\% da vazão total (100 L.dia ${ }^{-1}$ ); e Etapa III - 100\% da vazão total (200 L.dia ${ }^{-1}$ ) (vazão de recirculação), com duração de 13 e 17 semanas, respectivamente. As principais características físicas e operacionais (vazão e tempo de retenção hidráulica - TRH) do sistema de tratamento estão apresentadas na Tabela 1 .

O monitoramento foi realizado semanalmente nos seguintes pontos: EB: efluente bruto: afluente; SL1: saída da lagoa L1; SL2: saída da lagoa L2; SL3: saída da lagoa L3; e SFP: saída do FP. Foram medidos o oxigênio dissolvido (OD) $\left(\mathrm{mg} \cdot \mathrm{L}^{-1}\right)$, temperatura $\left({ }^{\circ} \mathrm{C}\right)$, $\mathrm{pH}$ e condutividade (ms/cm) in loco com sonda multiparâmetros (YSI 6600 V2). As variáveis físico-químicas e biológicas analisadas foram: demanda química de oxigênio (DQO, método do refluxo fechado com dicromato de potássio); demanda bioquímica de oxigênio ( $\mathrm{DBO}$, incubação e medidas manométricas HACH Track), carbono orgânico dissolvido (COD, SHIMADZU 500A); série de sólidos totais, fixos e voláteis e sólidos suspensos totais (ST, SF, SV, SST, por gravimetria); Amônia $\left(\mathrm{NH}_{4}-\mathrm{N}\right)$ e Nitrogênio Total Kjeldahl (NTK) (digestão e destilação VELP), Nitrito $\left(\mathrm{NO}_{2}-\mathrm{N}\right)$ e Nitrato $\left(\mathrm{NO}_{3}-\mathrm{N}\right)$ (cromatografia iônica DIONEX 120), cor (UC, espectrofotometria, $\lambda=254 \mathrm{~nm}$ ); turbidez (NTU, turbidímetro HACH); e clorofila $a$ (cl $a$, extração em álcool etílico), segundo o Standard Methods (APHA, AWWA, WEF, 2005).

Testes de toxidade aguda foram realizados utilizando-se o organismo-teste Daphnia magna segundo a NBR 12.713 (ABNT, 2003). Para cada amostra de lixiviado, foram preparadas cinco diluições (solução-teste) e um controle. O fator de diluição (FD) representa a 


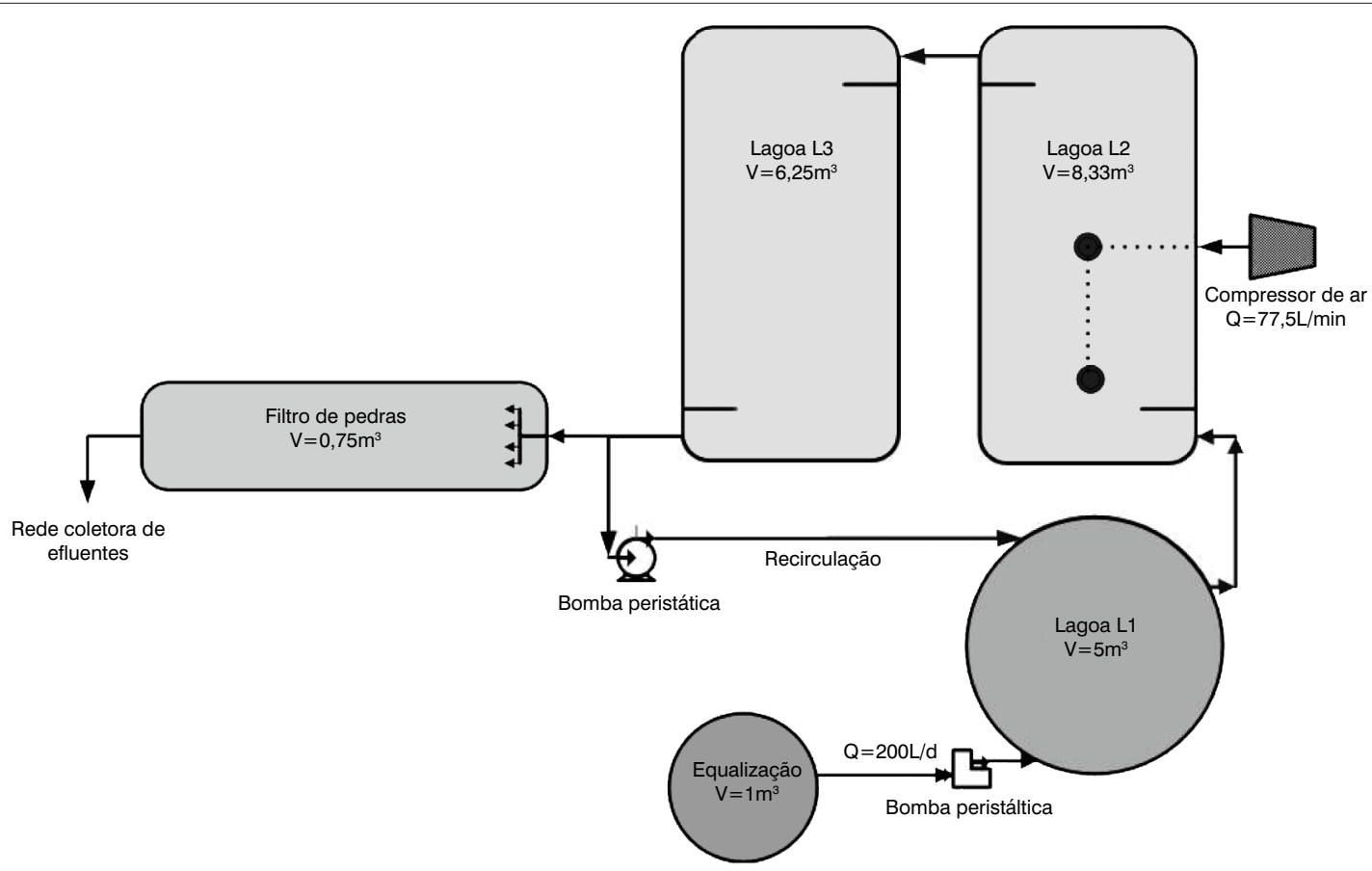

Figura 1 - Esquema do sistema de tratamento.

primeira de uma série de diluições de uma amostra na qual não mais se observam efeitos tóxicos agudos aos organismos-teste. O resultado do teste foi expresso em Concentração Efetiva Inicial Mediana - $\mathrm{CE}(\mathrm{I})_{50} 48 \mathrm{~h}$, que corresponde à concentração da amostra que causa efeito agudo a 50\% dos organismos expostos em 48 horas, nas condições de teste.

$\mathrm{Na}$ identificação fitoplânctonica, foram utilizadas chaves de classificação de Bicudo e Menezes (2005), procedendo-se até o nível mínimo de gênero. A identificação zooplanctônica foi feita de acordo com Sleigh (1989). As análises foram realizadas utilizando-se microscópio óptico binocular (Olympus BX-41) e microscópio invertido (Bioval XDS-1), com amostras frescas e/ou preservadas com solução de lugol acético (1:100) e refrigeradas. Análises FISH (hibridização fluorescente in situ, do inglês fluorescent in situ hybridization) foram realizadas com amostras das lagoas L2 e L3, segundo metodologia de Amann (1995), utilizando-se sondas específicas.

\section{Resultados e discussão}

As concentrações médias das variáveis $\mathrm{OD}, \mathrm{T}$ e pH, ao longo do sistema de tratamento, estão apresentadas na Tabela 2.

As temperaturas médias estiveram entre 16 e $25^{\circ} \mathrm{C}$, decrescendo entre as Etapas I a III. O pH apresentou-se elevado, com valores variando de 8,9 a 10,2, com características de lixiviado de aterro considerado de idade intermediária a velho (LANGE; AMARAL, 2009). Quanto ao OD, as concentrações médias encontradas nas lagoas fotossintéticas L2 e L3 variaram entre 1,9 e 3,7 mg. $\mathrm{L}^{-1}$; o FP
Tabela 1 - Características físicas e condições operacionais do sistema de tratamento

\begin{tabular}{|c|c|c|c|c|}
\hline Dimensões & L1 & L2 & L3 & FP \\
\hline Comprimento (m) & - & 4,36 & 4,36 & 3,0 \\
\hline Largura (m) & - & 2,40 & 2,40 & 0,5 \\
\hline Diâmetro (m) & 1,85 & - & - & - \\
\hline Profundidade $(m)$ & 1,85 & 0,80 & 0,60 & 0,5 \\
\hline Volume $\left(m^{3}\right)$ & 5,00 & 8,37 & 6,25 & 0,75 \\
\hline \multicolumn{5}{|l|}{ Etapa I - Sem recirculação } \\
\hline $\begin{array}{l}\text { Vazão de alimentação do sistema } \\
\left(\text { L.dia }{ }^{-1}\right)\end{array}$ & 200 & & & \\
\hline TRH (dias) & 25 & 42 & 31 & 4 \\
\hline \multicolumn{5}{|l|}{ Etapa II - recirculação 50\% } \\
\hline Vazão de recirculação (L.dia-1) & 100 & & & - \\
\hline Vazão total afluente $\left(\right.$ L.dia $\left.^{-1}\right)$ & 300 & 300 & 300 & 200 \\
\hline TRH (dias) & 17 & 28 & 21 & 4 \\
\hline \multicolumn{5}{|l|}{ Etapa III - recirculação 100\% } \\
\hline Vazão de recirculação (L.dia-1) & 200 & & & - \\
\hline Vazão total afluente (L.dia ${ }^{-1}$ ) & 400 & 400 & 400 & 200 \\
\hline TRH (dias) & 13 & 21 & 16 & 4 \\
\hline
\end{tabular}

L1: lagoa 1; L2: lagoa 2; L3: lagoa 3; FP: filtro de pedras; TRH: tempo de retenção hidráulica.

manteve-se sempre aeróbio, com concentrações médias de OD superiores a $3 \mathrm{mg} \cdot \mathrm{L}^{-1}$.

As cargas aplicadas às lagoas nas etapas do estudo estão apresentadas na Tabela 3, as quais para a DQO se assemelham àquelas utilizadas no tratamento de águas residuárias domésticas (VON SPERLING, 
2002) e foram elevadas para amônia, em virtude das características do lixiviado bruto. Devido às mudanças na vazão afluente, pelo aumento da recirculação do efluente, as cargas foram aumentando progressivamente ao longo das etapas. As lagoas trataram cargas volumétricas com remoções superiores a $70 \%$ para DQO e $90 \%$ para nitrogênio amoniacal nas Etapas I e II. O menor desempenho observado foi na Etapa III, quando as cargas aplicadas foram superiores devido à recirculação e variações na composição do lixiviado bruto. Para as cargas superficiais, as lagoas L2 e L3 apresentaram remoções superiores a $60 \%$ para DQO e entre 78 e $96 \%$ da carga amoniacal.

Para lixiviados de aterros sanitários, Leite et al. (2009), utilizando quatro lagoas rasas em série, aplicaram carga superficial de $3.676 \mathrm{~kg}$

Tabela 2 - Resultados para temperatura, oxigênio dissolvido e pH

\begin{tabular}{lcccc}
\hline Local & Etapa & OD $\left(\mathrm{mg} \cdot \mathrm{L}^{-1}\right)$ & $\mathrm{T}\left({ }^{\circ} \mathrm{C}\right)$ & $\mathrm{pH}$ \\
\hline EB & I & ND & $27 \pm 2$ & $9,6 \pm 0,2$ \\
& II & ND & $19 \pm 3$ & $9,9 \pm 0,1$ \\
& III & ND & $16 \pm 3$ & $9,8 \pm 0,1$ \\
\hline SL1 & I & ND & $28 \pm 2$ & $9,9 \pm 0,1$ \\
& II & ND & $20 \pm 3$ & $10,2 \pm 0,1$ \\
& III & ND & $15 \pm 3$ & $10,2 \pm 0,2$ \\
\hline SL2 & I & $3,3 \pm 0,8$ & $28 \pm 2$ & $9,7 \pm 0,1$ \\
& II & $3,7 \pm 1,7$ & $19 \pm 3$ & $9,7 \pm 0,1$ \\
& III & $1,8 \pm 0,6$ & $15 \pm 3$ & $9,8 \pm 0,1$ \\
\hline SL3 & I & $3,6 \pm 1,1$ & $26 \pm 2$ & $9,4 \pm 0,6$ \\
& II & $1,9 \pm 0,4$ & $18 \pm 2$ & $8,9 \pm 0,5$ \\
& III & $2,6 \pm 1,6$ & $16 \pm 3$ & $9,2 \pm 0,5$ \\
\hline FP & I & $3,5 \pm 1,5$ & $26 \pm 2$ & $9,4 \pm 0,6$ \\
& II & $5,6 \pm 0,4$ & $19 \pm 3$ & $9,6 \pm 0,1$ \\
& III & $3,6 \pm 2,2$ & $23 \pm 3$ & $9,2 \pm 0,8$ \\
\hline
\end{tabular}

ND: não detectado; I $(n=11)$, II ( $n=13)$, III $(n=17)$.

EB: efluente bruto; SL1: saída da Lagoa 1; SL2: saída da Lagoa 2; SL3: saída da Lagoa 3; FP: filtro de pedras; OD: oxigênio dissolvido.
DQO.ha ${ }^{-1} \cdot$ dia $^{-1}$ e $364 \mathrm{~kg} \mathrm{~N}-\mathrm{NH}_{4} \cdot \mathrm{ha}^{-1} \cdot \mathrm{dia}^{-1}$, obtendo remoção de DQO de 67\% e de amônia de 99,5\%; Santos et al. (2009), por sua vez, realizando tratamento combinado de lixiviados de aterro sanitário com esgoto doméstico, em sistema composto por uma lagoa facultativa e uma lagoa de maturação, para carga aplicada de $66 \mathrm{~g} \mathrm{DQO} \cdot \mathrm{m}^{-3} \cdot \mathrm{dia}^{-1}$, observaram remoções em torno de $45 \%$.

\section{Remoção da fração carbonácea}

$\mathrm{Na}$ Tabela 4, estão apresentadas as concentrações médias das principais variáveis representativas da matéria carbonácea de monitoramento do sistema de tratamento.

\section{Demanda química de oxigênio}

A recirculação do efluente teve participação na melhora da qualidade do efluente, embora as concentrações médias finais de $\mathrm{DQO}_{\mathrm{T}}$ ainda tenham se mostrado elevadas (> $400 \mathrm{mg} \cdot \mathrm{L}^{-1}$ ). Essa alta concentração remanescente deve-se aos compostos orgânicos recalcitrantes, geralmente presentes em grande quantidade nos lixiviados de aterros sanitários, como descrito por Thörneby et al. (2006), e também pela matéria algal em suspensão que foi retida apenas parcialmente no FP.

Na Figura 2, estão apresentados os resultados obtidos para a $\mathrm{DQO}_{\mathrm{T}}$ no efluente bruto (EB) e na saída do sistema de tratamento sem recirculação (0\%) e com recirculação (50 e 100\%), onde se observa que houve uma melhora na qualidade do efluente, em torno de $11 \%$, tendo em vista a mudança de 0 para $100 \%$ de recirculação. Para as três diferentes condições de tratamento, as remoções variaram entre 72 e $80 \%$.

Moravia et al. (2009) observaram, para sistema de lagoas aeradas, remoções de DQO na ordem de 34\% para concentrações afluente e

Tabela 3 - Cargas aplicadas às lagoas nas etapas do estudo

\begin{tabular}{|c|c|c|c|c|c|c|}
\hline Carga aplicada & Etapa/Recirculação & Lagoa L1 & Lagoa L2 & Lagoa L3 & Saida L3 & Remoção (\% \\
\hline $\mathrm{cov}$ & \multirow{4}{*}{$1 / 0 \%$} & 80 & 43 & 22 & 20 & 75 \\
\hline CV & & 40 & 23 & 6 & 1 & 98 \\
\hline $\cos$ & & - & 347 & 131 & 122 & $68^{*}$ \\
\hline CS & & - & 182 & 36 & 8 & $96^{*}$ \\
\hline cov & \multirow{4}{*}{$1 \mathrm{II} / 50 \%$} & 108 & 57 & 38 & 31 & 71 \\
\hline CV & & 60 & 32 & 11 & 4 & 93 \\
\hline $\cos$ & & - & 458 & 228 & 188 & $60^{*}$ \\
\hline CS & & - & 254 & 64 & 21 & $92^{*}$ \\
\hline cov & \multirow{4}{*}{ III/100\% } & 134 & 79 & 73 & 61 & 54 \\
\hline CV & & 62 & 36 & 20 & 10 & 84 \\
\hline $\cos$ & & - & 633 & 437 & 249 & $61^{*}$ \\
\hline CS & & - & 286 & 119 & 62 & $78^{*}$ \\
\hline
\end{tabular}

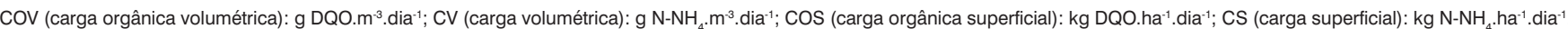
${ }^{*}$ Cargas superficiais removidas nas lagoas fotossintéticas (L2 e L3). 
Tabela 4 - Resultados das variáveis representativas da matéria carbonácea

\begin{tabular}{|c|c|c|c|c|}
\hline Local & Etapa & $\mathrm{DQO}_{\mathrm{T}}\left(\mathrm{mg} \cdot \mathrm{L}^{-1}\right)$ & $\mathrm{DBO}_{\mathrm{F}}\left(\mathrm{mg} \cdot \mathrm{L}^{-1}\right)$ & COD (mg.t-1) \\
\hline \multirow[t]{3}{*}{ EB } & 1 & $1990 \pm 378$ & $582 \pm 243$ & $441 \pm 229$ \\
\hline & ॥ & $2378 \pm 379$ & $442 \pm 149$ & $668 \pm 97$ \\
\hline & III & $2406 \pm 603$ & $663 \pm 261$ & $544 \pm 109$ \\
\hline \multirow[t]{3}{*}{ SL1 } & I & $1808 \pm 174$ & $539 \pm 281$ & $481 \pm 146$ \\
\hline & II & $1589 \pm 264$ & $489 \pm 107$ & $224 \pm 108$ \\
\hline & III & $1649 \pm 469$ & $399 \pm 387$ & $373 \pm 101$ \\
\hline \multirow[t]{3}{*}{ SL2 } & I & $681 \pm 224$ & $175 \pm 125$ & $227 \pm 15$ \\
\hline & ॥ & $791 \pm 233$ & $263 \pm 51$ & $461 \pm 252$ \\
\hline & III & $1139 \pm 477$ & $372 \pm 257$ & $302 \pm 239$ \\
\hline \multirow[t]{3}{*}{ SL3 } & I & $637 \pm 178$ & $116 \pm 57$ & $203 \pm 23$ \\
\hline & II & $653 \pm 194$ & $243 \pm 52$ & $194 \pm 104$ \\
\hline & III & $946 \pm 273$ & $192 \pm 196$ & $244 \pm 126$ \\
\hline \multirow[t]{3}{*}{ FP } & I & $562 \pm 101$ & $55 \pm 27$ & $154 \pm 41$ \\
\hline & II & $550 \pm 167$ & $76 \pm 37$ & $202 \pm 54$ \\
\hline & III & $487 \pm 142$ & $46 \pm 26$ & $101 \pm 25$ \\
\hline \multirow[t]{3}{*}{ Remoção (\%) } & I $(n=11)$ & 72 & 91 & 65 \\
\hline & II $(n=13)$ & 77 & 83 & 70 \\
\hline & III $(n=17)$ & 80 & 93 & 82 \\
\hline
\end{tabular}

efluente de 2.800 e $1.852 \mathrm{mg} . \mathrm{L}^{-1}$, respectivamente. Para diferentes tipos de sistemas de lagoas, Renou et al. (2008) relataram remoções de DQO variando entre 40 e $97 \%$. Os autores registraram a grande dependência do desempenho das lagoas com a temperatura, uma vez que esta afeta diretamente a atividade microbiana que ocorre no meio líquido. No presente estudo, porém, as temperaturas foram diminuindo entre as Etapas I e III, com uma diferença de cerca de $10^{\circ} \mathrm{C}$ entre essas etapas.

\section{Demanda bioquímica de oxigênio}

O aterro sanitário tem aproximadamente 20 anos. O lixiviado em estudo teve características de "lixiviado antigo", segundo classificação apresentada por Lange e Amaral (2009), com concentrações de DBO variando entre 400 e $800 \mathrm{mg} \cdot \mathrm{L}^{-1}$. A relação DBO/DQO foi de 0,28 (Etapa I), 0,19 (Etapa II) e 0,28 (Etapa III), indicando uma baixa fração orgânica biodegradável. Efluentes dessa natureza possuem em sua composição compostos recalcitrantes e matéria orgânica não biodegradável, que limitam sua tratabilidade (THÖRNEBY et al., 2006; OLIVERO-VERBEL; PADILLA-BOTTET; DE LA ROSA, 2008 ). Foram observadas remoções de $\mathrm{DBO}_{\mathrm{F}}$ de 90,83 e 93\%, com concentrações na saída do sistema de 55, 76 e 46 mg. L-1 , nas Etapas I, II e III, respectivamente. De acordo com a Legislação Ambiental de Santa Catarina - lei no 14.675 de 13 de abril de 2009 - Código Estadual do Meio Ambiente (ESTADO DE SANTA CATARINA, 2009), essa condição atende ao padrão de lançamento, desde que não altere as características do corpo receptor para a classe na qual ele se enquadra.

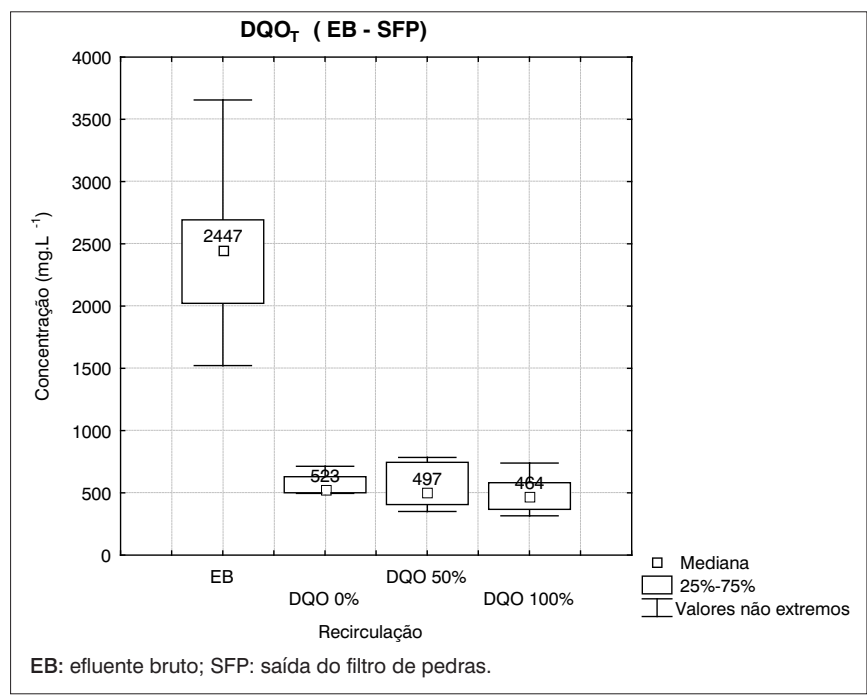

Figura 2 - Diagramas de caixa dos dados de $\mathrm{DQO}_{\mathrm{T}}\left(\mathrm{mg} \cdot \mathrm{L}^{-1}\right)$ nos diferentes períodos do estudo - valores das medianas.

Pesquisadores da Universidade Estadual de Londrina (UEL), Paraná, no âmbito do PROSAB/Edital 5, observaram em dois sistemas de tratamento (Sistema 1 - com lagoa de stripping e Sistema 2 - sem lagoa de stripping) remoções de cerca de 50\% da carga orgânica presente no lixiviado com concentração final de DBO de 70 mg..-1 (CASTILHOS Jr. et al., 2009). Igualmente, Frascari et al. (2004) apresentaram resultados de um sistema de 5 lagoas em série, para tratamento de lixiviado de aterro sanitário, em escala real, cujas eficiências médias, obtidas para período de 10 anos de monitoramento, foram de 40 e 64\% para DQO e DBO, com concentrações efluentes de 2.960 e 470 mg.L $\mathrm{L}^{-1}$, respectivamente. 


\section{Carbono orgânico dissolvido}

O EB apresentou concentrações de COD variando entre 500 e $600 \mathrm{mg} . \mathrm{L}^{-1}$; foram obtidas remoções de 65\% (Etapa I), 70\% (Etapa II) e $82 \%$ (Etapa III), com concentrações do efluente tratado de 154 , 202 e $101 \mathrm{mg} \cdot \mathrm{L}^{-1}$, respectivamente. O sistema de tratamento apresentou remoções $>70 \%$ para a $\mathrm{DQO}_{\mathrm{T}}, \geq 83 \%$ para a $\mathrm{DBO}_{\mathrm{F}} \mathrm{e} \geq 65 \%$ para o carbono orgânico dissolvido. Observa-se que, mesmo não sendo sua função principal, o filtro de pedras incrementou a remoção da matéria carbonácea, em todas as etapas, para essas variáveis. Os resultados alcançados nesta pesquisa retratam que o sistema de lagoas de estabilização com aeração e recirculação, mesmo sendo um processo biológico, alcançou remoções iguais ou superiores a processos físico-químicos de tratamento, que são mais onerosos e exigem mão de obra qualificada para sua operação como indicam, por exemplo, os estudos realizados por Silva, Dezotti e Sant'Anna (2004), com diferentes processos físico-químicos de tratamento de um lixiviado de aterro sanitário "antigo", com relação DBO/DQO de 0,04 e remoções de COT variando entre 15 e 24\% para o processo de coagulaçãofloculação, além de resultados negativos para o processo de ozonização. Gotvajn, Tišler e Zagorc-Končan (2009), por sua vez, avaliaram o processo de adsorção em carvão ativado, para lixiviado de aterro industrial, e obtiveram remoção do COD em torno de 60\% para uma relação DBO/DQO próxima a 0,6; para o processo de coagulação floculação, os mesmos autores relataram remoções máximas de $25 \%$ para dosagem de $1.000 \mathrm{mg} . \mathrm{L}^{-1}$ de $\mathrm{Al}_{2}\left(\mathrm{SO}_{4}\right)_{3}$ e de $28 \%$ para dosagem de $1.750 \mathrm{mg} . \mathrm{L}^{-1}$ de $\mathrm{FeCl}_{3}$.

\section{Sólidos suspensos totais, turbidez e cor}

Os sólidos fixos predominaram nesse tipo de efluente estudado, correspondendo a mais de $82 \%$ dos sólidos totais. O efluente tratado apresentou concentrações médias de SST de 120 mg.L.-1 (Etapa I), 98 mg. L $^{-1}$ (Etapa II) e 186 mg.L-1 (Etapa III), com remoções médias de 65, 83 e 68\%, respectivamente. Moravia et al. (2009), em lagoas aeradas, conseguiram remoções de $77 \%$ de SST, com concentração final de $17 \mathrm{mg} . \mathrm{L}^{-1}$, para TRH variando entre 7 e 14 dias. Para diferentes sistemas com lagoas, Renou et al. (2008) apresentaram remoções de SST compreendidas entre 30 e $40 \%$.

Os valores de turbidez na saída do sistema foram em média 29 (Etapa I), 15 (Etapa II) e 20 NTU (Etapa III), variando de acordo com as características do lixiviado e com o desenvolvimento algal nas lagoas. A remoção média na primeira etapa foi de $65 \%$ e nas duas etapas seguintes foi de $87 \%$. Para a cor, foram alcançadas remoções na ordem de 64 (Etapa I), 72 (Etapa II) e 67\% (Etapa III), com efluente final apresentando concentrações médias entre $1.230 \mathrm{e}$ 1.420 UC. Esses valores estão diretamente ligados aos sólidos fixos, devido à presença de compostos refratários. A turbidez pode ser removida por processos físicos, enquanto a cor exige processos mais complexos. Renou et al. (2008) relataram experiências com diferentes composições de sistemas de lagoas, em que a remoção de turbidez variou entre 30 e 40\%. Silva, Dezotti e Sant'Anna (2004) obtiveram remoções de cor da ordem de $70 \%$ para coagulação-floculação com $700 \mathrm{mg} . \mathrm{L}^{-1}$ de sulfato de alumínio e $78 \%$ em processo de ozonização com $1,5 \mathrm{gO}_{3} \cdot \mathrm{L}^{-1}$.

\section{Remoção da fração nitrogenada}

$\mathrm{Na}$ Tabela 5, estão apresentadas as concentrações médias das principais variáveis representativas da matéria nitrogenada, obtidas durante o monitoramento do sistema de tratamento.

\section{Nitrogênio amoniacal e NTK}

O NTK e o nitrogênio amoniacal foram bem removidos no sistema nas três condições estudadas ( $\geq 97 \%$ ). A fração amoniacal correspondeu a mais de $80 \%$ do NTK. Assim como observado para a matéria carbonácea, o FP também atuou na remoção dos compostos de nitrogênio, melhorando a qualidade do efluente que sai da L3 em cerca de 45\% (Etapas I e II) e 85\% (Etapa III) para o NTK; 65\% (Etapas I e II) e 94\% (Etapa III) para o nitrogênio amoniacal, além de ter removido o nitrito remanescente da L3 para valores inferiores a 5 mg.L-1 (Etapas I e III). Resultados obtidos para diferentes sistemas de lagoas mostram eficiências de remoção de 77\% (FRASCARI et al., 2004) e 80\% (RENOU et al., 2008), tanto para nitrogênio amoniacal quanto para NTK.

Ferreira, Lange e Von Sperling (2009) alcançaram remoções médias de 60\% de amônia em 3 lagoas aeradas, o que se deu principalmente através de mecanismos de arraste, favorecidos pela agitação resultante da aeração e pelos valores de $\mathrm{pH}$ das lagoas $(>8,0)$. Leite et al. (2009), por sua vez, sutilizando lagoas rasas, obtiveram eficiência de remoção de amônia de 99,5\% com concentração final de 5,3 mg. $\mathrm{L}^{-1}$ para carga aplicada de $364 \mathrm{~kg} \mathrm{~N}-\mathrm{NH}_{4} \cdot \mathrm{ha}^{-1}$. dia- ${ }^{-1}$ e TDH de 39,5 dias. Sistemas de tratamento estudados na UEL alcançaram remoção de amônia de 23\% quando havia lagoa de stripping e de 16\% sem lagoa de stripping; nos dois estudos, a formação de nitrito e nitrato foi menor do que a perda da amônia (CASTILHOS Jr. et al, 2009).

Os resultados obtidos para o nitrogênio amoniacal $\left(\mathrm{N}-\mathrm{NH}_{4}\right)$ no $\mathrm{EB}$, tratamento sem recirculação (0\%) e tratamento com recirculação (50 e 100\%) estão apresentados na Figura 3, em que se observa que no EB o valor da mediana do nitrogênio amoniacal foi de 1.490 mg. $\mathrm{L}^{-1}$, com variações nos valores de entrada, em função das características do efluente; no período sem recirculação, a mediana alcançada foi de 11 mg.L.-1; nos períodos seguintes (Etapas II e III), os valores de saída ficaram em 22 e $6 \mathrm{mg} . \mathrm{L}^{-1}$, respectivamente, confirmando para as três diferentes condições de tratamento uma remoção acima de $98 \%$, com concentrações finais que se enquadram nos padrões de lançamento de efluentes (CONAMA 357/05). 
Tabela 5 - Concentrações médias e desvio padrão das frações nitrogenadas e remoção de nitrogênio

\begin{tabular}{|c|c|c|c|c|c|}
\hline Local & Etapa & NTK (mg. L-1) $^{-1}$ & $\mathrm{~N}-\mathrm{NH}_{4}\left(\mathrm{mg} \cdot \mathrm{L}^{-1}\right)$ & $\mathrm{N}-\mathrm{NO}_{2}\left(\mathrm{mg} \cdot \mathrm{L}^{-1}\right)$ & $\mathrm{N}-\mathrm{NO}_{3}\left(\mathrm{mg} \cdot \mathrm{L}^{-1}\right)$ \\
\hline \multirow[t]{2}{*}{ EB } & 1 & $1231 \pm 143$ & $1001 \pm 120$ & ND & ND \\
\hline & II & $1630 \pm 258$ & $1473 \pm 246$ & ND & ND \\
\hline \multirow[t]{2}{*}{ SL1 } & 1 & $1325 \pm 170$ & $947 \pm 162$ & ND & ND \\
\hline & II & $926 \pm 279$ & $882 \pm 167$ & ND & ND \\
\hline \multirow[t]{3}{*}{ SL2 } & 1 & $252 \pm 39$ & $190 \pm 38$ & $101 \pm 56(n=10)$ & $2,43 \pm 1(n=4)$ \\
\hline & II & $223 \pm 114$ & $223 \pm 106$ & $191 \pm 71(n=9)$ & $2 \pm 19(n=5)$ \\
\hline & III & $295 \pm 98$ & $310 \pm 126$ & $53 \pm 43(n=17)$ & $2 \pm 0,16(n=2)$ \\
\hline \multirow[t]{2}{*}{ SL3 } & 1 & $65 \pm 129$ & $40 \pm 22$ & $22 \pm 0(n=1)$ & ND \\
\hline & II & $91 \pm 45$ & $74 \pm 41$ & $101 \pm 20(n=11)$ & $3,49 \pm 2(n=2)$ \\
\hline $\mathrm{FP}$ & III & $19 \pm 8$ & $9 \pm 8$ & $7 \pm 14(n=2)$ & ND \\
\hline \multirow[t]{3}{*}{ Remoção (\%) } & I & 97 & 99 & - & - \\
\hline & II & 97 & 98 & - & - \\
\hline & III & 99 & 99 & - & - \\
\hline
\end{tabular}

ND: não detectado; I $(n=11)$, II $(n=13)$, III $(n=17)$.

\section{Nitritos e nitratos}

De acordo com os resultados apresentados na Tabela 5, verifica-se uma queda na concentração de amônia na lagoa L2 em 79 (Etapa I), 75 (Etapa II) e 58\% (Etapa III). Nessa lagoa, onde havia aeração artificial do meio, registrou-se a ocorrência de nitritos nas três etapas (101, 191 e 53 mg. $\left.\mathrm{L}^{-1}\right)$, mas a transformação para nitrato não ocorreu de forma significativa ( $\left.2 \mathrm{mg} . \mathrm{L}^{-1}\right)$, o qual só foi detectado em apenas algumas amostras.

Os valores de OD nas lagoas L2 e L3 apresentaram-se adequados ao mínimo de 2 mg. $\mathrm{L}^{-1}$, recomendado por Rittmann e McCarty (2001) para a ocorrência de nitrificação em reatores biológicos. Observou-se um decréscimo do $\mathrm{pH}$ em cerca de uma unidade nas etapas estudadas, como consequência do consumo da alcalinidade pela nitrificação. No entanto, esta ocorreu de forma parcial (nitritação). Esse comportamento também foi relatado por vários autores, para tratamento de lixiviados de aterros sanitários, em sistemas de lagoas e diferentes concepções de reatores biológicos (ALTINBAS, 2009; ALVIN et al., 2009; GANIGUÉ et al., 2007).

As análises FISH, efetuadas com amostras da lagoa L2, nas três etapas, revelaram a ocorrência de bactérias oxidadoras de amônia (NOS), Nitrosomonas (NEU) e Nitrobacter (NIT). Ou seja, havia a presença dos dois grupos de nitrificantes; porém, algum fator/condição inibiu a atividade das Nitrobacter, havendo o acúmulo de nitrito no meio.

Parkes, Jolley e Wilson (2007) observaram que o processo de nitrificação em lagoa aerada foi limitado pela alcalinidade, no qual

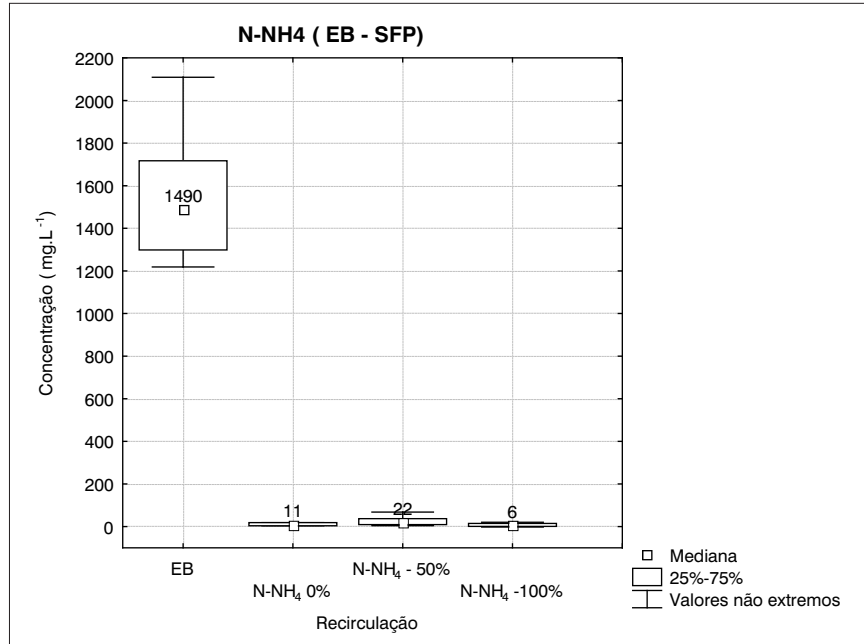

EB: efluente bruto; SFP: saída do filtro de pedras.

Figura 3 - Diagramas de caixa dos dados de $\mathrm{N}^{-\mathrm{NH}_{4}}\left(\mathrm{mg} \cdot \mathrm{L}^{-1}\right)$ nos diferentes períodos do estudo.

a concentração afluente de amônia era de $3.480 \mathrm{mg}$. L $\mathrm{L}^{-1} \mathrm{e}$ a efluente, de 630 mg. L $^{-1}$ (82\% de remoção). No presente estudo, a alcalinidade média do efluente bruto foi de $4.400 \mathrm{mg} \mathrm{CaCO}_{3} \cdot \mathrm{L}^{-1}$, não havendo, portanto, limitação desta para a ocorrência da nitrificação.

Segundo Hossaka et al. (2009), o acúmulo de nitritos durante a oxidação da amônia está diretamente relacionado com o pH e com a temperatura, uma vez que esses parâmetros influenciam diretamente as concentrações de amônia livre que, por sua vez, interferem 
diretamente na atividade das bactérias Nitrosomonas. Esses autores, bem como Ganigué et al. (2007), constataram a importância do pH sobre a atividade das bactérias oxidadoras de amônia, para a manutenção da amônia livre $\left(\mathrm{NH}_{3}\right)$ em níveis favoráveis ao acúmulo de nitritos, impedindo que a oxidação avançasse até o estágio de nitrato.

Alvim et al. (2009), estudando a remoção de nitrogênio amoniacal de lixiviados de aterros sanitários, utilizando sistema de lodos ativados em bateladas, demonstraram que na oxidação do nitrogênio amoniacal a nitrito em ambiente aerado, o pH de 7 a 9 contribuiu para manter as condições de amônia livre $\left(\mathrm{NH}_{3}\right)$ em níveis que inibem as bactérias oxidantes de nitrito, impedindo a formação de nitratos.

De acordo com Henze et al. (1997), as bactérias que oxidam amônia até nitrito são inibidas com concentrações de amônia livre a partir de $10 \mathrm{mg} \mathrm{N}-\mathrm{NH}_{3} \cdot \mathrm{L}^{-1}$, havendo inibição total com $150 \mathrm{mg} \mathrm{N}-\mathrm{NH}_{3} \cdot \mathrm{L}^{-1}$, enquanto a inibição das bactérias que oxidam nitrito até nitrato ocorre em uma faixa menor, dando início a uma concentração de amônia livre de 0,1 mg N-NH$\cdot \mathrm{L}^{-1}$, ocorrendo inibição completa com 1,0 mg $\mathrm{N}-\mathrm{NH}_{3} \cdot \mathrm{L}^{-1}$. O cálculo da amônia livre na L2 revelou concentrações variando entre 150 e $200 \mathrm{mg} \mathrm{N}-\mathrm{NH}_{3} \cdot \mathrm{L}^{-1}$, indicando que esse foi o fator preponderante para o acúmulo de nitrito nessa lagoa.

\section{Avaliação microbiológica}

A avaliação microbiológica da lagoa L1 detectou a presença de bacterioplâncton, constituído por organismos morfologicamente classificados como cocos, espirilos e bastonetes. A ausência de grupos fitoplanctônicos nessa unidade foi também verificada, uma vez que seu funcionamento ocorre em anaerobiose e com total ausência de luz.

As análises FISH, efetuadas com amostras da lagoa L2 nas três etapas, apresentaram bactérias oxidadoras de amônia (NOS) entre 30 e 40\% (NOS/DAPI [4,6 diamidino-2-phenylindol] = 30-40/100); Nitrosomonas (NEU) entre 15 e 25\% (NEU/DAPI = 15-25/100); e Nitrobacter (NIT) entre 15 e 25\% (NIT/DAPI = 15-25/100). Amostras coletadas na lagoa L3 não puderam ser avaliadas em função da grande interferência de material algal na leitura das sondas.

Tabela 6 - Resultados dos ensaios de toxicidade

\begin{tabular}{lccc|} 
Local & $\begin{array}{c}\mathrm{CE}(\mathrm{I})_{50} 48 \mathrm{~h} \\
\text { Etapa I }\end{array}$ & $\begin{array}{c}\mathrm{CE}(\mathrm{I})_{50} 48 \mathrm{~h} \\
\text { Etapa II }\end{array}$ & $\begin{array}{c}\mathrm{CE}(\mathrm{I})_{50} 48 \mathrm{~h} \\
\text { Etapa III }\end{array}$ \\
\hline EB & 2,44 & 2,28 & 3,12 \\
\hline SL1 & 4,41 & 4,29 & 4,90 \\
\hline SL2 & 7,73 & 49,99 & 17,68 \\
SL3 & 45,06 & 70,71 & 35,35 \\
\hline SFP & 84,08 & 61,64 & Pouco tóxico \\
\hline FD & 4 & 3 & 2 \\
\hline Redução toxicidade (\%) & 97 & 96 & 98 \\
\hline
\end{tabular}

EB: efluente bruto; SL1: saída da lagoa 1; SL2: saída da lagoa 2; SL3: saída da lagoa 3; SFP: saída do filtro de pedras; FD: fator de diluição.
Nas unidades fotossintetizantes (L2 e L3), verificou-se, no contexto taxonômico, baixa diversidade fitoplânctonica, composta de 6 taxas principais, entre gêneros e espécies, sendo 3 da classe Chlorophyceae, 1 Cryptophyceae e 2 Bacillariophyceae.

Verificou-se na lagoa L2 a presença de algas verdes dos gêneros Chlorella, Chlamydomonas, diatomáceas e ciliados, presumindo-se, dessa forma, que a aeração da lagoa possibilitou o aparecimento de maior diversidade de organismos. Na L3, observou-se pouca variação, mantendo-se a predominância e abundância de algas flageladas do gênero Chlamydomonas, que se apresentaram com uma ocorrência numérica superior a 50\% do número total de indivíduos amostrados.

A presença marcante do gênero Chlamydomonas, em ambas as lagoas fotossintéticas (L2 e L3), de acordo com Beyruth (1996), pode ter ocorrido pelo fato de esses organismos serem frequentes em lagoas de estabilização, servindo para caracterizar as fases ou condições de tratamento de acordo com suas exigências tróficas, suportando perfeitamente ambientes ricos em matéria orgânica em decomposição. A elevada densidade desse gênero deve-se, provavelmente, ao fato de esses organismos serem mais bem adaptados às condições extremas de contaminação do lixiviado, levando, assim, à exclusão dos demais grupos (FERNANDES, 2009). Uma monocultura de Chlamydomonas também foi obtida nos estudos realizados por Leite et al. (2009) em lagoas rasas tratando lixiviado de aterro sanitário.

Devido à aeração na L2, os valores de clorofila $a$ foram menores do que na L3, exclusivamente fotossintética, variando entre 4 e 120 $\mu \mathrm{g} . \mathrm{L}^{-1}$ na L2, e entre 320 e $440 \mu \mathrm{g} . \mathrm{L}^{-1}$ na L3. A Etapa II foi aquela em que as concentrações estiveram mais elevadas nessas lagoas. A radiação acumulada mensalmente foi de 368, 252 e 297 W.m². mês ${ }^{-1}$, durante as etapas I, II e III, respectivamente, evidenciando que não houve uma relação direta entre as concentrações de clorofila a e esse parâmetro. Esse comportamento acontece quando o fitoplâncton presente nas lagoas tem grande mobilidade, o que foi o caso do estudo, com predominância de Chlamydomonas. O FP removeu, em média, 49 (Etapa I) e 85\% (Etapas II e III) de clorofila $a$, apresentando concentrações na saída entre 37 e $226 \mu \mathrm{g}$. L ${ }^{-1}$.

\section{Testes toxicológicos}

Os resultados obtidos nos ensaios de toxicidade e seus respectivos fatores de diluição (FD) podem ser visualizados na Tabela 6, na qual se verifica que, durante todo o monitoramento, o EB apresentou-se bastante tóxico, com concentrações da $\mathrm{CE}(\mathrm{I})_{50} 48 \mathrm{~h}$ menores que 3,5. Ao passar pelas unidades de tratamento, observa-se diminuição dessa toxicidade, chegando a reduções significativas na saída do sistema (> 95\%), sendo a maior de 98\% com FD igual a 2, obtida na Etapa III, caracterizando o efluente como "pouco tóxico".

No geral, o tratamento atendeu à portaria 017/2002 da Fundação do Meio Ambiente do Estado de Santa Catarina (FATMA), a qual estabelece FD máximo de 8 para efluentes de aterros sanitários. 
Ferreira, Mannarino, Moreira, Arias e Bila (2009) avaliaram a eficiência do tratamento combinado do lixiviado de aterro sanitário em estação de tratamento de esgoto (ETE Icaraí), realizando ensaios toxicológicos com peixes Danio rerio e microcrustáceos Daphnia similis. Os ensaios mostraram que, embora o lixiviado tenha elevada toxicidade variando entre 32 a 64 FD, o tratamento combinado apresentou baixa toxicidade (8 FD), atendendo à legislação estadual do Rio de Janeiro. OliveroVerbel, Padilla-Bottet e de la Rosa (2008), para aterro sanitário localizado em Cartagena, Colômbia, observaram que a toxicidade do lixiviado era dependente do aumento na fração orgânica, representada pela DQO. Em vários aterros na Suécia e Lituânia, Svensson et al. (2005) atribuíram a toxicidade do lixiviado à presença de amônia e poluentes orgânicos, com resultados similares encontrados no Brasil (SILVA; DEZOTTI; SANT'ANNA, 2004) e na Itália (PIVATO; GASPARI, 2006).

\section{Conclusão}

O sistema de tratamento conseguiu tratar efetivamente o lixiviado de aterro sanitário, deixando o efluente final com características dentro do exigido pela legislação ambiental quanto à matéria carbonácea (DBO) e nitrogenada (nitrogênio amoniacal).

O efeito da recirculação melhorou o desempenho do sistema de tratamento, apresentando, para a condição de 100\% de recirculação do efluente, remoções da matéria carbonácea em cerca de 93\% de $\mathrm{DBO}_{\mathrm{F}}, 80 \%$ de $\mathrm{DQO}_{\mathrm{T}}$ e $82 \%$ de COD; remoções da matéria nitrogenada em 99\% para nitrogênio amoniacal e NTK; e um efluente com características de "pouco tóxico" (FD = 2).

Observou-se a presença marcante do gênero Chlamydomonas nas lagoas fotossintéticas (L2 e L3). Na lagoa com aeração (L2), houve nitrificação parcial, com acúmulo de nitritos.

\section{Agradecimentos}

Os autores agradecem ao Conselho Nacional de Desenvolvimento Científico e Tecnológico (CNPq) pela bolsa de estudos, ao Programa de Pesquisa em Saneamento Básico (PROSAB) - Edital 5: Resíduos Sólidos, e a seus financiadores FINEP, CNPq, CTHidro e CAIXA.

\section{Referências}

ALTINBAS, M. Environmental technologies to remove nitrogen from contaminated leachates. In: Cervantes, F.J. Environmental Technologies to Treat Nitrogen Pollution.London: IWA Publishing, 2009, p. 191-229.

ALVIM, C.A.N. et al. Remoção de nitrogênio amoniacal de lixiviados de aterro sanitário utilizando sistema de lodos ativados em batelada. In: CONGRESSO BRASILEIRO DE ENGENHARIA SANITÁRIA E AMBIENTAL, 25, 2009, Recife. Anais... Recife: ABES, 2009.

AMANN, R. In situ identification of microorganism by whole cell hybridization with rRNA-targeted nucleic acid probes. In: AKKERMANS, A.D.L.; VAN ELSAS, J.D.; de BRUIJN, F.J. (Eds.). Molecular Microbial Ecology Manual. New York: Springer, 1995, p. 1-15.

APHA, AWWA, WEF. Standard Methods for the Examination of Water and Wastewater. 21. ed. Washington DC: APHA, AWWA, WEF, 2005.

ASSOCIAÇÃO BRASILEIRA DE NORMAS TÉCNICAS (ABNT). ABNT NBR 12.713. Ecotoxicologia aquática - Toxicidade aguda - Método de ensaio com Daphnia spp. (Cladocera, Crustacea). Rio de Janeiro: ABNT, 2003.

BEYRUTH, Z. Comunidade fitoplanctônica da Represa de Guarapiranga: 1991-1992. Aspectos Ecológicos, Sanitários e Subsídios para Reabilitação da Qualidade Ambiental. Tese (Doutorado em Saúde Ambiental). Universidade de São Paulo, São Paulo, SP, 1996

BICUDO, C.E.M.; MENEZES, M. Gêneros de algas de águas continentais do Brasil. Chave para identificação e descrições. São Carlos: RiMa,2005.
CASTILHOS Jr, A.B. et al. Tratamento de Lixiviados de Aterro em Sistema de Lagoas. In: GOMES, L.P. Estudos de Caracterização e Tratabilidade de Lixiviados de Aterros Sanitários para as Condições Brasileiras. PROSAB 5 - Tema 3, v. 5, Rio de Janeiro: ABES, 2009, p. 140-171.

ESTADO DE SANTA CATARINA. Lei no 14.675, de 13 de abril de 2009 Institui o Código Estadual do Meio Ambiente e estabelece outras providências. Disponível em: < http://www.sc.gov.br/downloads/ Lei_14675.pdf >

Portaria da Fundação do Meio Ambiente $n^{\circ}$ 17, de 18 de abril de 2002. Disponível em: <www.fatma.sc.gov.br>.

FERNANDES, H. A dinâmica da biota em um sistema de lagoas de estabilização para tratamento de lixiviado de aterro sanitário. Dissertação (Mestrado em Engenharia Sanitária e Ambiental). Universidade Federal de Santa Catarina, Florianópolis, SC, 2009.

FRASCARI, D. et al. Long-term characterization, lagoon treatment and migration potential of landfill leachate: a case study in an active Italian landfill. Chemosphere, v. 54, n. 3, p. 335-343, 2004.

FERREIRA, C.F.A.; LANGE, L.C.; VON SPERLING, M. Desempenho de sistema de lagoas aeradas para o tratamento de lixiviado estabilizado de aterro sanitário. In: Congresso Brasileiro de Engenharia Sanitária e Ambiental, 25, 2009. Recife, Anais... Recife: ABES, 2009.

FERREIRA, J.A.; MANNARINO, C.F.; MOREIRA, J.C.; ARIAS, A.R.L.; BILA, D.M. Ensaios ecotoxicológicos para avaliação de tratamento combinado de lixiviado de aterro de resíduos sólidos urbanos 
em estação de tratamento de esgotos. In: Congresso Brasileiro de Engenharia Sanitária e Ambiental, 25, 2009. Recife, Anais... Recife:ABES, 2009.

GANIGUÉ, R. et al. Partial ammonium oxidation to nitrite of high ammonium content urban landfill leachates. Water Research, v. 41, n. 15, p. 3317-3326, 2007.

GOTVAJN, A. Z.; TIŠLER, T.; ZAGORC-KONČAN, J. Comparison of different treatment strategies for industrial landfill leachate. Journal of Hazardous Material, v. 162, n. 2-3, p. 1446-1456, 2009.

HENZE, M. et al. Wastewater treatment: biological and chemical processes. Berlin: Springer-Verlag, 1997.

HOSSAKA, A.L. et al. Avaliação da formação de nitritos em sistema de lodos ativados em batelada no tratamento de lixiviados de aterro sanitário visando a desnitrificação de via curta. In: Congresso Brasileiro de Engenharia Sanitária e Ambiental, 25, 2009, Recife. Anais... Recife: ABES, 2009.

KJELDSEN, P.; CHRISTOPHERSEN, M. Composition of leachate from old landfills in Denmark. Waste Management \& Research, v. 19, n. 3, p. 249-256, 2001.

LANGE, L.C.; AMARAL, M.C.S. Geração e Características do Lixiviado. In: GOMES, L.P. Estudos de Caracterização e Tratabilidade de Lixiviados de Aterros Sanitários para as Condições Brasileiras. PROSAB 5 - Tema 3, v. 5, Rio de Janeiro: ABES, 2009, p. 27-59.

LEITE, V.D. et al. The removal of ammonia from sanitary landfill leachate using a series of shallow waste stabilization ponds. In: IWA SPECIALIST GROUP CONFERENCE ON WASTE STABILIZATION PONDS, 8, 2009, Belo Horizonte. Anais... Belo Horizonte, 2009.

MORAVIA, W.G. et al. Dimensionamento e avaliação de lagoas aeradas para tratamento de lixiviados de aterro sanitário estabilizado. In: CONGRESSO BRASILEIRO DE ENGENHARIA SANITÁRIA E AMBIENTAL, 25, 2009, Recife. Anais... Recife: ABES, 2009

OLIVERO-VERBEL, J.; PADILLA-BOTTET, C.; DE LA ROSA, O. Relationships between physicochemical parameters and the toxicity of leachates from a municipal solid waste landfill. Ecotoxicology and Environmental Safety, v. 70, n. 2, p. 294-299, 2008.
PARKES, S.D.; JOLLEY, D.F.; WILSON, S.R. Inorganic nitrogen transformation in the treatment of landfill leachate with a high ammonium load: A case study. Environmental Monitoring Assessments, v. 124, n. 1-3, p. 51-61, 2007.

PIVATO, A.; GASPARI, L. Acute toxicity test of leachates from traditional and sustainable landfills using luminescent bacteria. Waste Management, v. 26, n. 10, p. $1148-1155,2006$

RENOU, S. et al. Landfill leachate treatment: Review and opportunity. Journal of Hazardous Materials, v. 150, n. 3, p. 468-493, 2008

RITTMANN, B.E.; McCARTY, P.L. Environmental Biotechnology: principles and applications. New York: McGraw-Hill, 2001.

SANTOS, A.S.P. et al. Avaliação do tratamento combinado de lixiviados de aterros sanitários com esgoto doméstico em lagoas de estabilização. In: CONGRESSO BRASILEIRO DE ENGENHARIA SANITÁRIA E AMBIENTAL, 25, 2009, Recife. Anais... Recife: ABES, 2009.

SILVA, A.C.; DEZOTTI, M.; SANT'ANNA JR., G.L. Treatment and detoxification of a sanitary landfill leachate. Chemosphere, v. 55, n. 2 , p. 207-214, 2004

SISINNO, C.L. et al. Toxicity evaluation of a municipal dump leachate using zebrafish acute tests. Bulletin of Environmental Contamination and Toxicology, v. 64, n. 1, p. 107-113, 2000.

SLEIGH, M.A. Protozoa and other protists. London: Edward Arnold, 1989.

SVENSSON, B.M. et al. Artemia salina as test organism for assessment of acute toxicity of leachate water from landfills. Environmental Monitoring Assessment, v. 102, n. 1-3, p. 309-321, 2005.

THÖRNEBY, L. et al. The performance of a natural treatment system for landfill leachate with special emphasis on the fate of organic pollutants. Waste Management \& Research, v. 24, n. 2, p. 183-194, 2006.

VON SPERLING, M. Princípios do tratamento biológico de águas residuárias. Volume 3: lagoas de estabilização. 2. ed. Belo Horizonte: UFMG, 2002.

WISZNIOWSKI, J. et al. Landfill leachate treatment methods: A review. Environmental Chemistry Letters, v. 4, n. 1, p. 51-61, 2006. 